\title{
INCÊNDIO
}

\section{UM RISCO CONSTANTE COM ELEVADO POTENCIAL DE PERIGO}

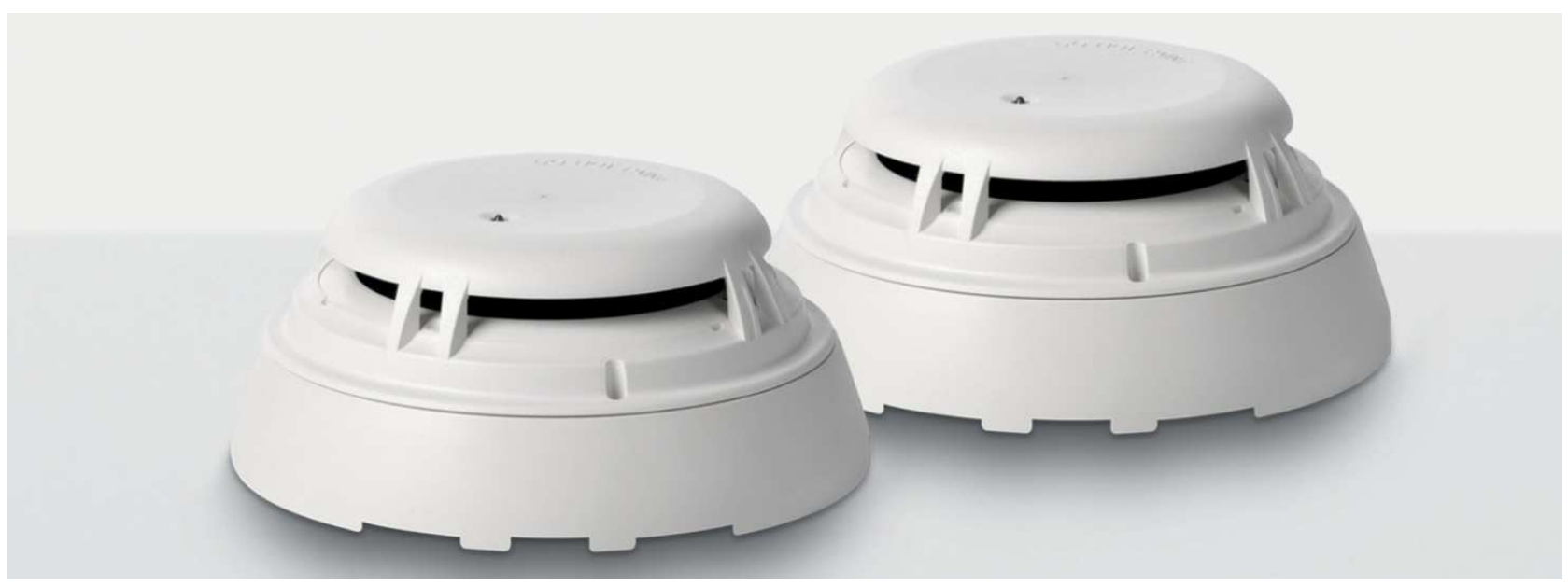

1

Generalidades

Desde a idade média, quando ardiam cidades inteiras, a humanidade tem aprendido muito e tem desenvolvido constantes esforços para evitar e circunscrever os incêndios. Estes esforços, no entanto, foram compensados pelo surgir de outras fontes de ignição e da crescente cargas combustíveis.

Hoje, praticamente todos os lares e empresas possuem computadores, televisores, lâmpadas halogenas, máquinas de café e outros aparelhos elétricos, bem como equipamentos de aquecimento e de ar condicionado, etc. A maioria destes dispositivos incluem uma unidade de alimentação e outros módulos eletrônicos, constituindo, assim, potenciais fontes de ignição.

Mas os incêndios também podem ser estabelecidas de forma intencional. A percentagem de incêndios de origem criminosa já é de 25 a 40\%, e os valores estão a aumentar [1]. Os incêndios provocados intencionalmente propagam-se frequentemente muito mais rapidamente tornando o seu combate extremamente difícil. Em média, esses tipo de incêndios são três vezes mais dispendiosos que a média das ocorrências dos incêndio[2].
Numa sociedade afluente, os edifícios são frequentemente mobilados com tecidos, carpetes, etc. Além disso, a utilização de materiais mais económicos, projetados para processos fáceis e moldáveis com materiais sintéticos, está permanentemente a aumentar. Além do aumento da carga combustível, essas substâncias são na sua maioria altamente inflamáveis e reagem como aceleradores dos incêndios. Este efeito é muito mais fatal do que o revelaria a mera carga combustível.

A conflagração libera aproximadamente tanta energia quanto uma central nuclear - tais conflagrações pode chegar a várias centenas de $\mathrm{MW}$ até alguns GW. Um incêndio limitado a um papel durante o qual $3 \mathrm{~g}$ de papel são queimadas por segundo já gera $40 \mathrm{~kW}$ e uma altura de $0,8 \mathrm{~m}$ chama.

Além do calor, cada incêndio, seja ele grande ou pequeno, produz resíduos tóxicos e gases de fumos altamente tóxicos. Esses gases contêm, entre outras substâncias, o monóxido de carbono, o gás de ácido clorídrico, gás clórico, vários compostos de enxofre, óxidos de nitrogênio (NOx), o gás de ácido cianídrico e muitas outras substâncias altamente tóxicas, mesmo fosgênio. A perda de vidas humanas e prejuízos financeiros causados direta ou indiretamente pelos fumos de gases é elevada. 
Por toda a Europa, mais de 4000 pessoas morrem a cada ano em ocorrências com causas em incêndio [3] - a maioria delas por intoxicação de fumos. Contudo é difícil avaliar o número aproximado de pessoas feridas - pode ascender a dez vezes mais de feridos graves e centenas de vezes em feridos ligeiros. No total, isso equivale a cerca de meio milhão de pessoas que são vítimas de incêndios todos os anos, e que, em parte, sofrem danos permanentes.

As despesas com danos diretamente relacionados com incêndios na Europa atingem de 1 a 3 por cento de um décimo PIB, isto significa que os danos diretamente causados por incêndios na Europa Ocidental representa mais de 15 mil milhões de euros. Consecutivamente os danos indiretos podem ser dez vezes mais elevados. Fazendo a comparação: O limite superior das despesas dos agregados familiares da UE-25 em 2005 era de cerca de 120 mil milhões de euros. As verificações mostraram que a maior parte destes danos são causados por gases nos fumos e os seus constituintes corrosivos. Os danos causados pelo fumo é maior em cerca de dez a cem vezes do que os danos pelo fogo real. Aproximadamente um terço dos danos dos fumos pode ser rastreada até ao ácido clorídrico $(\mathrm{HCl})$, libertado pelo fogo, o que resulta em corrosão das instalações e dos dispositivos.

Para uma empresa particular pode ser fatal. De acordo com estimativas de especialistas [7], uma conflagração de um incêndio nas instalações de uma empresa pode ter os seguintes efeitos:

- Cerca de um terço das empresas em causa, os danos de causados diretamente pelo incêndio resultam em falência.

- Outro terço das empresas em causa, a perda de clientes resulta em falência num prazo de três anos.

- O restante um terço muitas vezes tem de se fundir com outras empresas ou necessita de ser vendido.

Às vezes, porém, a empresa tem robustez para subsistir.
Os danos causados pelos incêndios mostra que a prevenção de incêndios, a deteção de incêndios e o combate aos incêndios são temas que devem ser abordados com especial atenção.

A figura 1 mostra algumas das centrais de deteção de incêndios da SIEMENS.
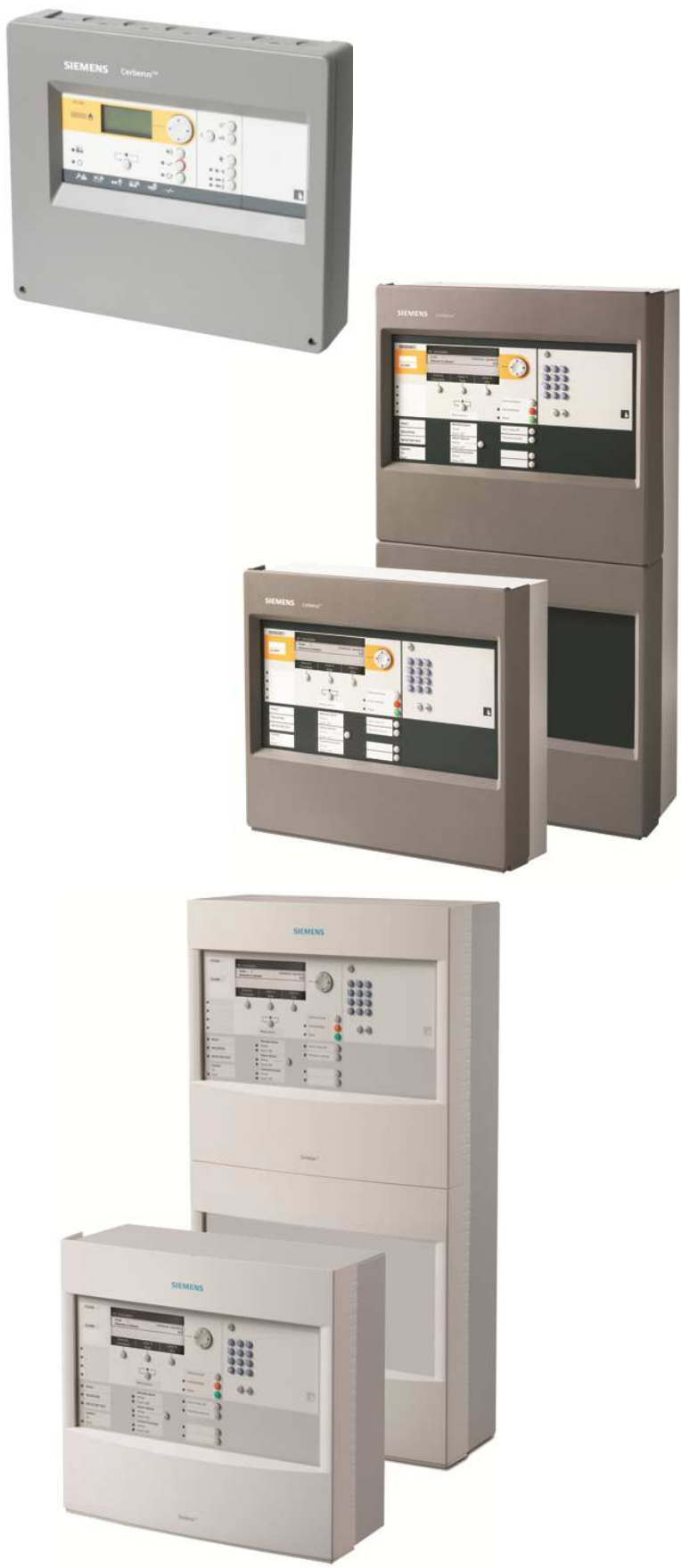

Figura 1. Centrais de deteção de incêndio Siemens 


\section{Conceito de proteção integral contra incêndios}

A implementação da cadeia de medidas de "prevenção deteção - combate - aprendizagem" pode ser representado como um circuito fechado, como o representado na figura 2.

Se os danos não podem ser prevenidos, o combate a incêndios entra em ação. É crucial que a proteção preventiva contra incêndios que garanta um alarme precoce e que a propagação geográfica do incêndio possa ser limitada.

Cada ocorrência deve ser prevista e estimada. Se o seu alcance for bastante reduzido, as medidas a serem introduzidas são limitadas à própria empresa.

Em caso de incêndios, a sociedade é a principal interessada em evitá-los no futuro. A experiência adquirida com essas ocorrências podem, assim, ser integradas nos regulamentos de proteção contra incêndios.

Estas duas formas de atuar garantem que as ocorrências se tornam menos frequentes e que as restantes ocorrências serão menos prejudiciais e menos urgentes.

\section{Proteção técnica contra incêndios}

A proteção técnica de incêndios compreende equipamentos e sistemas que servem para a segurança pessoal e mitigação de danos em caso de incêndio.

\subsection{Definições}

Uma "instalação" é a coletividade de todos os dispositivos instalados num edifício, dispositivos que interagem de modo que o objetivo do sistema possam ser cumpridos. Por exemplo, em instalações de deteção de gás, os detetores de gás, as unidades de controlo e os dispositivos de alarme interagem para alertar e proteger as pessoas dos gases.

Um "sistema" é a coletividade de todos os produtos necessários para configurar uma determinada instalação, harmonizado pelo fornecedor do sistema para que eles interagem sem problemas. A comunicação fácil entre detetores e unidade de controlo, por exemplo, devem ser sincronizados.

Um "produto" é um dispositivo individual utilizado num sistema ou numa instalação.

O sistema é composto por componentes de um ou vários produtos.

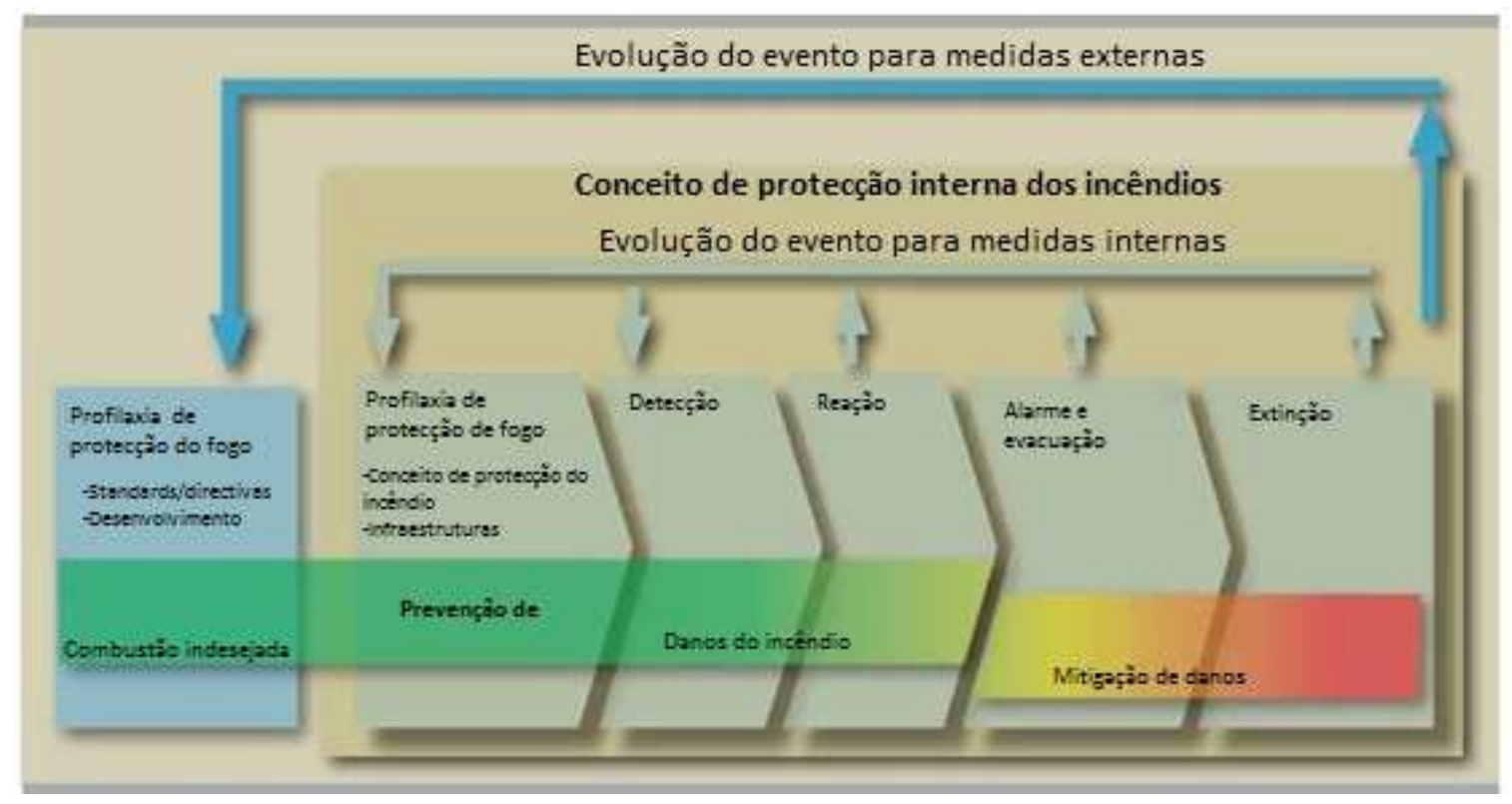

Figura 2. Conceito de proteção integral contra incêndios 


\subsection{Sistemas de aviso de gás}

Os sistemas de aviso de gás detetam concentrações perigosas de gases ou vapores no ambiente. Em caso de perigo, eles controlam automaticamente:

- Dispositivos de alarme acústicos e visuais para alertar as pessoas;

- Chamada para as pessoas de controlo e responsáveis do edifício;

- Sistemas de ventilação, sistemas de alimentação de gás, bombas, motores e válvulas.

\subsection{Sistemas de deteção de incêndio}

Sistemas de deteção automática de incêndio permitem uma deteção precoce de incêndios e a inicialização de funções de controlo pré-programadas. Isto inclui:

- Alertar as pessoas nas zonas de perigo;

- Chamada para a extinção de incêndio e dos meios de intervenção;

- Ativação dos sistemas para limitar a propagação do fogo e do fumo, por exemplo, fechar portas corta-fogo e registos corta-fogo;

- Ativação dos sistemas de extração de fumos e calor;

- Desligar sistemas técnicos (equipamentos) das fontes de alimentação;

- Controlo dos sistemas de automação de edifícios, especialmente sistemas de aquecimento, de ventilação e elevadores;

- Ligar a iluminação de emergência;

- Ativação dos sistemas de evacuação;
- Ativação de sistemas de extinção fixos.

Com um sistema de deteção de incêndio não automático, os alarmes são acionados manualmente. A presença de pessoas é um pré-requisito para se iniciar um alarme.

Um sistema de deteção de incêndio não automático pode também ser parte de um sistema de deteção de incêndios automático. No entanto, as funções de controlo ativadas manualmente são idênticos aos dos sistemas automáticos de deteção de incêndio.

O "alarme falso" é um alarme que foi acionado sem a ocorrência de um incêndio.

A prática na deteção de incêndios tem revelado que os falsos alarmes causam problemas graves.

Em toda a Europa, cerca de 90 a 95\% de todos os alarmes acionados por sistemas de deteção de incêndio são falsos alarmes. O seu significado pode ser representado com mais de 200.000 tentativas desnecessárias dos bombeiros na Alemanha [8] , em grande parte devido a falsos alarmes.

A figura 3 mostra uma solução de extinção de incêndios num datacenter.

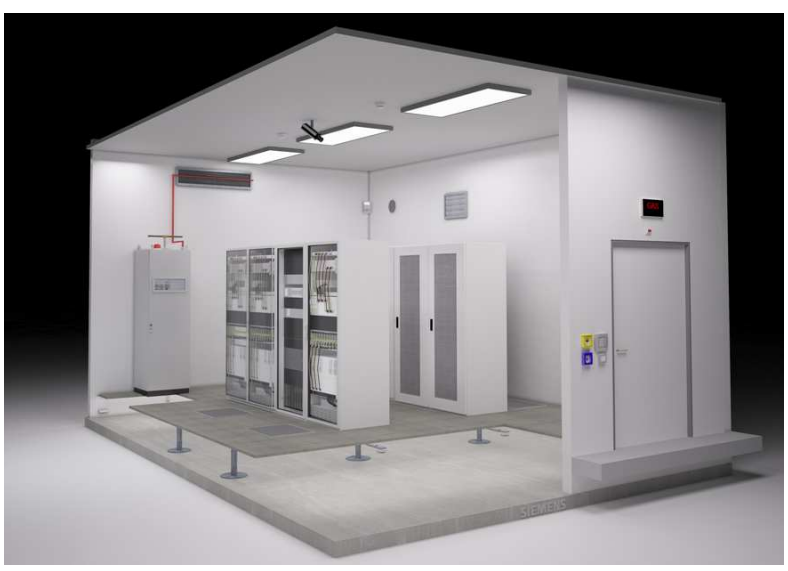

Figura 3. Soluções para datacenters 


\subsection{Sistemas de combate a incêndios}

Os dispositivos de extinção e as instalações de extinção para o combate ao manual ao incêndio são meios para acelerar e facilitar o combate do incêndio no local. Isto inclui:

- Hidrantes de parede;

- Colunas de extinção a água (seco / húmido);

- Hidrantes;

- Botões de alarme manual.

Elevadores de incêndio servem para o transporte de bombeiros e dos seus equipamentos, bem como para salvaguardar a pessoas com deficiência. Existem exigências especiais para os elevadores de incêndio, que geralmente também são utilizados normalmente como meio de transporte habitual.

Meios de comunicação de emergência permitem a comunicação dos bombeiros uns com os outros, bem como com os responsáveis do edifício. Normalmente, os sistemas de telefone bombeiros são utilizados para esse fim e são mais comuns nos Estados Unidos.

\subsection{Sistemas de Extinção de Incêndio}

Em caso de um elevado risco - principalmente em bens valiosos - pode ser instalado um sistema fixo de extinção automática.

Existem sistemas de extinção a água, espuma, pó e gás.

A base de cada tipo de sistema de extinção pode ser dividido em diferentes subsistemas e variantes, em parte, com base em diferentes princípios.

A figura 4 mostra um exemplo de um sistema de extinção de incêndios.
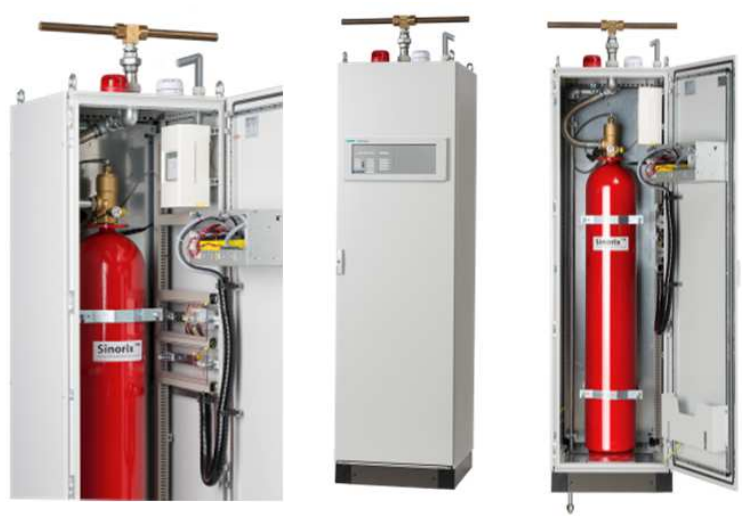

Figura 4. Sistema de extinção de incêndios compacto

\section{Deteção de incêndios}

\subsection{Introdução}

A incumbência de um sistema de deteção automática de incêndio é detetar um incêndio o mais cedo possível, para ativar o alarme e as funções de controlo pré-programadas. A experiência em sistemas de deteção de incêndio permite que a de deteção de incêndio atue mais cedo e assim minimizar os danos que poderão ser causados pelo incêndio. Através de uma escolha ideal dos produtos, juntamente com o conhecimento adequado, é possível criar sistemas que praticamente excluem os falsos alarmes.

Um sistema de deteção de incêndio consiste na unidade de controlo, os periféricos, tais como detetores de incêndio e os contactos, assim como os dispositivos de alarme e de controlo que são ativados pela unidade de controlo.

Para a seleção, definição e localização dos detetores de incêndio, é fundamental considerar - além da presença do risco predominante - o tipo de fogo expectável, a altura da sala, as condições ambientais tais como mudanças de ambiente e possíveis fenómenos enganosos. Em áreas de elevado risco, os detetores de incêndio multisensor, com processamento de sinal baseado no conhecimento e na experiência, são utilizados com mais frequência. Para riscos médios e inferiores os detetores de fumo, geralmente são aplicados detetores óticos com processamento de sinal convencional (tecnologia algorítmica). 
O conhecimento e a experiência, da Siemens, nos detetores de incêndio permitem uma configuração exata do comportamento detetor que satisfaça as condições ambientais e os fenómenos enganosos prevalecentes. Um detetor de incêndio em um quarto de hospital deve responder de uma forma completamente diferente de um detetor de incêndio numa fundição.

Quando se projetam os detetores de incêndio, deve-se ter a certeza quais os fenómenos de incêndio (fumo, calor, radiação, gás) que abrangem os detetores de incêndio, dando especial atenção à construção de teto (por exemplo, as vigas do teto, telhado especial ou formas de teto), e às possíveis divisões por recantos nas paredes, móveis, equipamentos ou acessórios.

Nos espaços onde ocorrem elevados fenómenos enganosos, a ideal disposição dos detetores de incêndio é de principal importância. Mesmo pequenas mudanças na posição do detetor pode trazer melhorias significativas na imunidade aos fenómenos enganosos, sem reduzir a confiabilidade de deteção.

Para selecionar a unidade de controlo da deteção de incêndio deve ser tida em consideração a facilidade na utilização, um elevado grau de flexibilidade e um grau muito elevado de funcionamento sem falhas. A unidade de controlo é o ponto de interação entre as pessoas e o sistema, deve portanto, representar o alarme e a falha de processamento de forma fácil e intuitiva.

A elevada flexibilidade no funcionamento em rede e uma parametrização que facilite as extensões ou adaptações do funcionamento sistema, para as mudanças dos requisitos do cliente.

A operacionalidade de um sistema de deteção de incêndio é fundamental, razão pela qual uma fonte de alimentação para emergência é uma função integrada de operação, que são um requisito obrigatório, tornando possíveis os alarmes de incêndio, mesmo em caso de uma falha de um módulo ou de energia.
Por razões económicas, a tecnologia de um sistema de deteção de incêndios, é escolhida de acordo com os requisitos e a situação de risco específica. Para um prédio de escritórios, um sistema de deteção de incêndio com botoneiras manuais e detetores óticos de fumo com processamento de sinal normal é normalmente suficiente, mas se é as instalações de produção de uma indústria química deve ser protegida, por exemplo, pela utilização da tecnologia avançada.

Com um portfólio abrangente de produtos, detetores de incêndio altamente confiáveis com tecnologia multissensorial e com a utilização de uma lógica excecional, alta flexibilidade da unidade de controlo de deteção de incêndio e sua ligação aos sistemas de gestão de perigos, são temas a ter em conta na escolha de um sistema de deteção de incêndio.

\subsection{Fundamentos do fogo}

O conhecimento da eclosão de um incêndio e seu desenvolvimento é decisiva para a prevenção e combate aos incêndios.

Para garantir uma deteção rápida e fiável, em caso de incêndio, é também importante se estar familiarizado com os diferentes fenómenos do incêndio e os possíveis tipos de fogo.

Os quatro temas seguintes serão tratados em detalhe adiante:

- Eclosão de um incêndio

- Desenvolvimento de um incêndio

- Fenômenos de fogo

- Tipos de fogo 


\subsection{Eclosão de um incêndio}

Para o desencadear de incêndio deve estar disponível o material combustível (carburante) e um agente oxidante (geralmente oxigénio).

O nosso ambiente é, em grande parte, composto por materiais combustíveis - e oxigênio disponível é quase sempre suficiente.

Existe contudo uma outra condição que deve ser cumprida para um fogo se iniciar: A energia de ignição deve ser a força condutora para iniciar a oxidação.

As fontes de energia para a ignição são múltiplas: descarga elétrica (por exemplo, raios), curto-circuito, faíscas, superfícies quentes (lâmpadas, equipamentos de aquecimento, etc), a exposição direta às chamas ou feixe de luz, para citar apenas os mais importantes.

Se ocorre um incêndio, este fornece a energia necessária para manter o processo de combustão.

Um fogo ocorre, portanto, pela interação de combustível, oxigênio e calor (energia), conforme representado na figura 5.

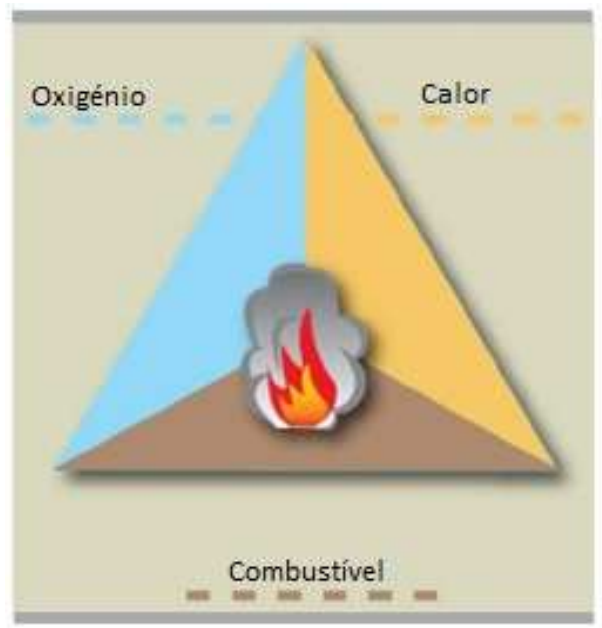

Figura 5.Triângulo do fogo

\subsection{Desenvolvimento de um incêndio}

Além dos processos de tipo explosão, fogo normalmente desenvolve-se mais ou menos rapidamente, dependendo do material combustível.

Quando o combustível e o oxigénio disponíveis são suficientes para o início do desenvolvimento de um incêndio, a sua amplitude determinada pela energia disponível.

Especialmente o fogo flamejante libera uma grande quantidade de energia, resultando num crescimento exponencial do incêndio nesta fase, conforme representado na figura 6.

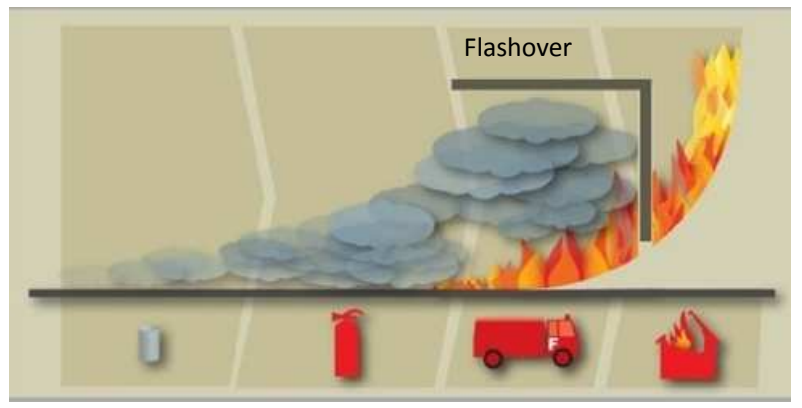

Figura 6. Desenvolvimento típico de um incêndio

Como representado na Figura 6, a maioria dos incêndios passa pelas seguintes fases e eventos:

\section{- Fase inicial}

O fogo incipiente pode ser extinto com alguns decilitros de água; ocorre pouco fumo visível, mas são criados especialmente aerossóis invisíveis.

\section{- Fase Latente}

Nesta fase, o fogo pode ser extinto por meio de um extintor de incêndio ou de um agente extintor similar. Surge fumo visível e parcialmente denso. Frequentemente a combustão é incompleta, razão pela qual, bastante quantidade de CO (tóxico) é produzido nesta fase. 


\section{- Fase ardente}

Estamos diante de um fogo aberto que deve ser extinto pelos bombeiros. Como a energia disponível é suficiente, o processo de combustão é bastante completa, resultando numa maior produção de $\mathrm{CO} 2$.

\section{- Flashover}

A transição entre um fogo flamejante em chama e um fogo total é chamado flashover. Esta é a propagação explosiva do fogo, que acontece exatamente no ponto em que os gases e aerossóis produzidos durante as fases anteriores inflamam e levam o fogo a todos as partes atravessadas pelos gases dos fumos.

\section{- Fogo Total}

Nesta fase, o fogo atingiu as partes maiores do edifício. $\mathrm{Na}$ maioria dos casos, o edifício ou o sector do incêndio não podem ser salvos e os corpos de bombeiros concentram os seus esforços na proteção dos edifícios vizinhos e nos sectores do incêndio.

Por estas razões a deteção de incêndios deve ocorrer o mais cedo possível, de modo que a intervenção possa começar antes do flashover. Incêndios incipientes, devem ser detetados, o mais tardar, na fase precoce ou na fase latente, de modo que haja tempo suficiente para a intervenção. O problema é que a fase precoce e a fase de combustão lenta pode ser completamente diferente na intensidade e na duração. Alguns fogos latentes podem estar a arder por horas ou até mesmo dias, antes que ocorra um fogo com chama.

Nos incêndios em líquidos, não há fase latente; eles desenvolvem-se diretamente para as chamas. Com tais incêndios, o tempo de intervenção é extremamente curto. Normalmente os danos apenas podem ser limitados por um sistema de extinção automática. Claro, existem outras possibilidades, tais como medidas construtivas, para retardar a propagação do incêndio, prolongando assim o tempo de intervenção - mas isso geralmente é muito caro.
Da análise ao desenvolvimento típico de um incêndio, podemos concluir que quanto mais cedo for detetado um incêndio, mais tempo há para ser combatido, logo menos danos. A deteção precoce é possível, portanto, é a chave para minimizar os danos e ganhar tempo precioso para a intervenção.

\subsection{Fenómenos do incêndio}

Os fenómenos do incêndio são valores físicos que estão sujeitas a mudança mensurável durante o desenvolvimento de um incêndio (por exemplo, o aumento da temperatura de obscurecimento ou chamas).

Os processos dos materiais em combustão podem ser vistos principalmente a partir da perspetiva de uma conversão de energia e de substâncias. A conversão energética liberta energia para o meio ambiente.

A conversão produz substancialmente - dependendo das substâncias presentes no incêndio - produtos em qualquer estado físico, variando de não-tóxicos para os altamente tóxicos.

A conversão energética libera energia por radiação e por convecção.

A gama de radiação libertada durante um incêndio pode ser dividido, por comprimento de onda, em radiação ultravioleta (UV), luz visível e infravermelha (IR).

Liberação de energia por convecção realiza-se essencialmente através do meio ambiente. Em primeiro lugar, a energia cinética das moléculas de ar aumenta, resultando num aumento da temperatura. A expansão associada conduz a um fluxo de ar ascendente. Devido a este fluxo, o ar mais frio, por consequência o oxigénio, é conduzido para o foco do incêndio. Esses processos também podem levar a flutuações de pressão periódicas que são compreendidos com o som em determinadas faixas de frequência (por exemplo, o estalido típico de um incêndio). 
A conversão de substâncias que ocorrem em caso de incêndio é caracterizada por as várias reações químicas que podem ocorrer no centro do incêndio, de acordo com as substâncias presentes.

A conversão substancial de um incêndio é determinado pelas diferentes reações químicas que se podem passar num incêndio. A conversão de produtos sólidos ou líquidos tendem a permanecer na base do incêndio (por exemplo, as cinzas) ou são distribuídos para o ambiente diretamente pelo incêndio. Neste último caso, eles formam um denominado aerossol, que são finamente distribuídas, misturadas com meio ambiente, em forma sólidas ou líquidas. A conversão de produtos gasosos espalham-se sempre pelo ar.

\section{Tipos de fogo}

Os fenômenos que ocorrem com um fogo latente ou chama diferem em termos de tipo e intensidade.

A principal propriedade da pirólise do fogo é que ele não se desenvolve independente, mas requere o fornecimento contínuo de nova energia. $O$ incêndio pode ser extinto por cessação do fornecimento de energia. A propagação do tipo de fogo é assim limitada à dimensão da fonte de calor, razão pela qual também se pode falar de sobreaquecimento acompanhada da decomposição química. Assim que a temperatura de ignição é atingida, o incêndio desenvolve-se para uma incandescência ou mesmo uma chama.

O fogo brilhante é um processo independente. Nas brilhantes e elevadas temperaturas são produzidas partículas produzidas que são relativamente pequenas. As partículas visíveis são apenas uma pequena parte do espectro de partículas produzidas. Típico para um fogo de incandescência são incêndios incipientes em fardos feno ou algodão.

Característico para as chamas - com a exceção de incêndios em álcool - é a produção de fuligem, ou seja, fumo negro. Embora também aqui, a maior parte das partículas produzidas está na gama das não-visíveis.

Estudos têm mostrado que, em quase todos os casos, incluindo a fase inicial e fase de combustão lenta, são produzidas mais partículas invisíveis do que os visíveis.

Resumindo, podemos afirmar que grandes volumes de aerossóis voláteis do fogo são produzidos em quase todos os incêndios hostis. O fumo tornou-se assim o fenómeno mais importante de um incêndio para uma deteção precoce. Dependendo do tamanho e concentração de aerossóis no incêndio, estes podem ser visíveis ou invisíveis. Em geral, os aerossóis dos incêndios são de 10 a 10.000 vezes o tamanho das moléculas de gás.

\section{Sistema de Deteção de Incêndio}

\subsection{Introdução}

A principal tarefa de um sistema de deteção automático de incêndio é identificar de forma confiável um incêndio e o mais cedo possível, para ativar os alarmes e as funções de controlo pré-programadas.

A periferia compreende todos os elementos de campo que obtém a informação do estado real no local, que é transmitido para a unidade de controlo sob a forma de níveis de perigo.

A inteligência, os detetores automáticos de incêndio, detetam e analisam os diferentes fenómenos de incêndio no local e automaticamente reportam os perigos existentes, para a unidade de controlo.

Os botões de alarme manual servem para a ativação direta do alarme pelas pessoas presentes na zona em perigo.

Os contatos automáticos (por exemplo, para ativação de um sistema de extinção de sprinkler) transmitem um alarme de incêndio de forma indireta.

O sistema de deteção de incêndio é monitorizado, controlado e operado pela unidade de controlo, que avalia as mensagens de perigo a partir dos dispositivos periféricos e ativa os alarmes e o controlo do incêndio das instalações. Além disso, ela serve para a operação do próprio sistema de deteção de incêndios. 
As medidas desencadeadas pela unidade de controlo servem para alarme e intervenção. Dispositivos de alarme visual e acústico informam as pessoas no edifício e chama para os responsáveis pela segurança e combate ao incêndio. Os comandos ativam os sistemas de extração de fumos e sistemas fixos de extinção. A orientação dos caminhos de saída e os sistemas de evacuação por voz, evacuam as pessoas do edifício em segurança.

A figura 7 mostra um esquema simplificado da arquitetura de um sistema de deteção automática de incêndios (SADI).

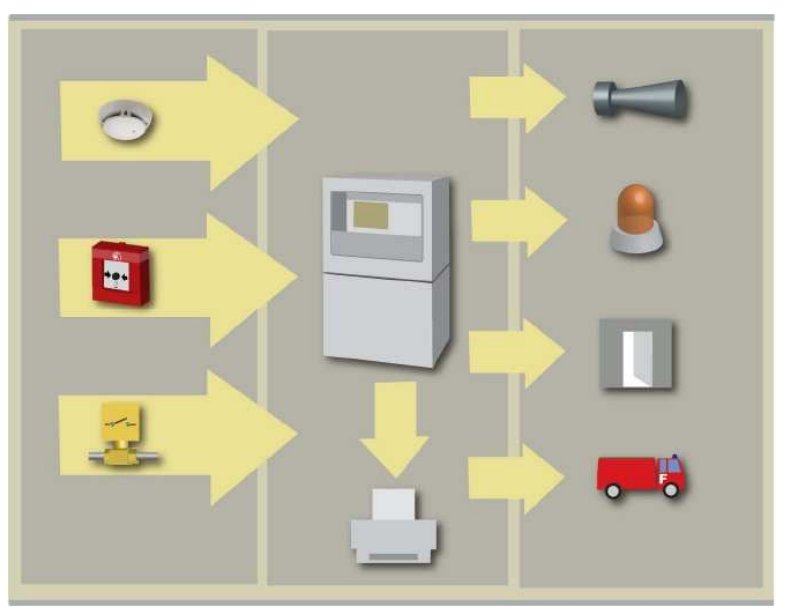

Figura 7. Arquitetura geral de um SADI

\subsection{Seleção correta do detetor de incêndio}

A seleção de ótima de um detetor de incêndio é com base nos fenómenos de incêndio de esperados, produzidos por um fogo incipiente. Para um edifício de escritórios, são selecionados preferencialmente os detetores de fumo, como neste caso os fogos irão produzir fumo claramente visível tanto na fase incipiente e na posterior. Numa área de armazenamento, aonde são armazenados combustíveis de líquidos, os detetores de chama e/ou detetores de térmicos, seria a escolha certa.

Para se ser capaz de detetar com segurança todos os incêndios incipientes, pode ser necessário combinar diferentes tipos de detetores de incêndio.
A figura 8 mostra o comportamento de resposta dos detetores de incêndio aos diferentes teste de fogo da EN54.

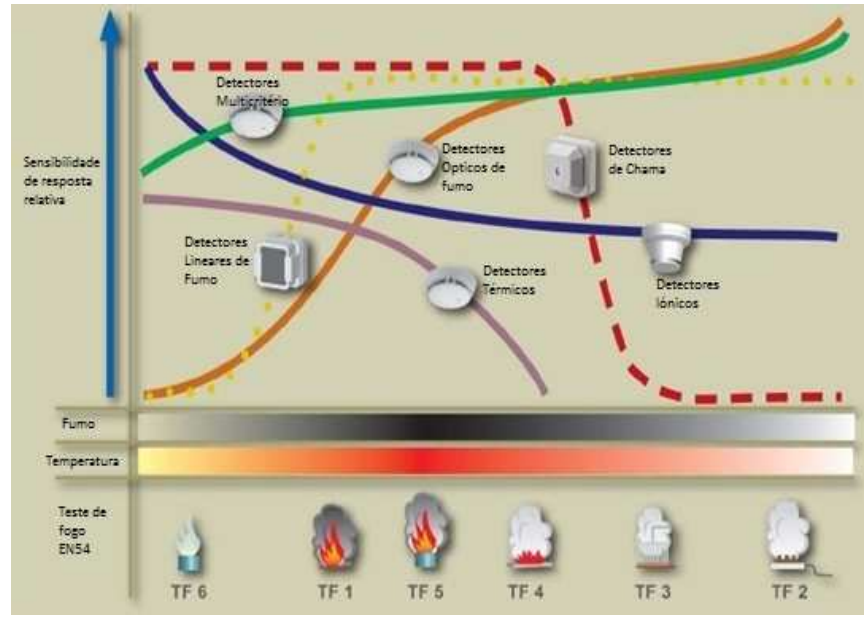

Figura 8. Comportamento de resposta dos detetores de incêndio aos diferentes teste de fogo da EN54

\subsection{Tipos de detetores}

\subsubsection{Síntese}

Um detetor de incêndio deve ser capaz de detetar precocemente e de forma confiável no mínimo um dos fenómenos de fogo que podem ser esperados. A altura do espaço, as condições ambientais e possíveis fenómenos enganosos devem ser tidos em conta. O impacto de fenómenos enganosos sobre o comportamento da deteção podem ser reduzidos através de medidas como o posicionamento correto, a configurações adequada dos detetores ou separação estrutural nos compartimento de incêndio.

Para selecionar o melhor e o mais adequado detetor de incêndio, os riscos e os custos também desempenham um papel importante.

Se uma área monitorizada com elevado risco de incêndio e em que podem ocorrer fortes fenómenos enganosos, as interrupções de funcionamento devem ser evitadas de qualquer forma, mas a deteção de incêndio deve ser tão precoce, confiável e imune aos enganos quanto possível. 
Este é o caso com as instalações de soldadura automática, por exemplo. Nessas áreas, são utilizados diferentes tipos de detetores de incêndio, que são muitas vezes combinados, por exemplo, detetores de incêndio multisensor e detetores de chama. Num edifício de escritórios com proibição de fumar, o uso de detetores de fumos é completamente suficiente.

Para uma utilização em ambientes sujos ou áreas de risco de explosão, detetores de incêndio devem atender a requisitos especiais concebidos para as respectivas áreas.

\subsubsection{Tecnologias de deteção}

\section{i) Tecnologia algorítmica}

Os detetores de incêndio com base na tecnologia algorítmica realizam análises complexas ao sinal em curtos intervalos e processam grandes volumes de dados. Eles estão equipados com um microprocessador. Os sinais dos sensores são divididos em componentes matemáticas e são compensados com os algoritmos definidos e programados (regras matemáticas). A característica destes algoritmos é definida pela sua parametrização. A comparação dos valores calculados com os valores predefinidos fornecidos no detetor, resulta no correspondente do nível de perigo.

Os detetores de incêndio com tecnologia algorítmica não garantem automaticamente um comportamento excelente na deteção, pois é afetada pela forma como os sinais do sensor são discriminados, pelas aplicações das regras matemáticas, pelos conjuntos de parâmetros disponíveis e pela comparação com os valores predefinidos fornecidos no detetor. Este é o lugar onde o conhecimento entra em jogo. Os detetores que utilizam a tecnologia algorítmica tem as seguintes propriedades:

- Os sinais dos sensores de deteção: comportamento é dinâmico e apenas é possível quando o sinal de progressão é observado e comparado ao longo do período total de tempo em que o respectivo fenómeno é eficaz.
- A progressão do sinal é a junção dos seguintes fatores determinantes:

- Sinal do sensor: A intensidade do sinal (amplitude)

- Taxa de variação: A variação do sinal no sensor

- Flutuação: As mudanças bruscas do sinal no sensor

- As regras matemáticas: As regras matemáticas devem ser estabelecidas de tal forma que, em combinação com os conjuntos de parâmetros disponíveis, permitam todos os tipos de desenvolvimento de incêndio.

- Os parâmetros de ajuste: Os parâmetros de ajuste é um conjunto de dados que tem um impacto sobre o regras matemáticas e sobre as comparações com os valores padrão. Ao se definir um respectivo conjunto de parâmetros, as regras matemáticas fixas são especificamente definidas para os fenómenos de incêndio e para as condições ambientais que podem ser esperadas, sendo que os resultados são comparados com os padrões correspondentes. Se um detetor de incêndio está instalado em uma sala de produção, um ajuste nos parâmetros deve ser definido para aferir as mudanças bruscas, normalmente causadas por fenômenos enganosos, como sendo relativamente insignificante. Se o mesmo detetor de incêndio está instalado em um quarto de hospital, no entanto, um conjunto de parâmetros devem ser selecionados que responder às rápidas mudanças dos sinais do sensor, garantindo o mais cedo possível o alarme de incêndio. Com o conhecimento e a experiência aplicada aos detetores pode ser escolhida uma grande variedade de conjuntos nos parâmetros, sendo eles adequados para todos os tipos de aplicações especiais.

- A comparação com os valores predefinidos fornecidos no detetor: Os valores predefinidos fornecidos nos detetores são baseados num grande número de fogos reais, refletindo as características de muitos tipos diferentes de incêndios. 
A comparação entre os valores calculados e os resultados dos valores do nível de predefinidos (por exemplo, 1=risco possível, 2=perigo, 3=alarme). As avaliações adicionais permitem informações sobre o estado do detetor (por exemplo, de sujidade ou falha, nível de diagnóstico).

\section{ii) ASAtechnology ${ }^{\mathrm{TM}}$ (Análise avançada de sinais)}

ASAtechnology ${ }^{\mathrm{TM}}$ é a continuação do desenvolvimento da tecnologia algorítmica. O comportamento de deteção pode ser adaptada a cada aplicação em causa, devido aos conjuntos de parâmetros correspondentes. A principal diferença entre esta tecnologia e a tecnologia algorítmica é a interpretação em tempo real da situação e, com base nisso, o impacto dinâmico do conjunto de parâmetros selecionados. Os parâmetros individuais dos conjuntos de parâmetros selecionados já não são estáticos; são modificados de acordo com os sinais dos sensores. O campo de aplicação do detetor é aumentado, o que é equivalente a uma dinâmica de deteção maior. Em caso de incêndio, um detetor baseado na ASAtechnology ${ }^{\mathrm{T} м}$ responde de forma mais sensível. Em caso de engano, é mais robusto do que um detetor usando o tecnologia algorítmica. O resultado, é uma deteção de incêndio sem precedentes, combinado com uma imunidade inimitável ao engano.

\subsubsection{Detetores de fumo do tipo pontuais}

Os detetores de fumos do tipo pontuais são utilizados em áreas onde se espera que os incêndios incipientes produzam fumo e onde poucos ou nenhuns fenómenos enganosos possam ocorrer. Os detetores de fumo de luz difusa são particularmente adequados para a deteção de partículas de fumo na luz, enquanto que o vigor dos detetores de fumo por ionização reside na deteção de pequenas partículas de fumo escuras. Como é utilizada uma fonte de radiação radioativa e devido aos problemas resultantes da eliminação, os detetores de ionização são utilizados cada vez com menos frequência.
As áreas típicas para aplicação dos detetores de fumo do tipo pontuais são:

- Locais onde é proibido fumar;

- Hospitais e lares de idosos;

- Escritórios;

- Museus e salas de exposição

- Salas de armazenamento de papel, eletrônicos de consumo, etc

- Instalações de produção de produtos eletrônicos;

- Salas de computadores/datacenters (em combinação com um sistema de aspiração);

- Salas de comunicação.

A figura 9 mostra um detetor ótico de fumos.

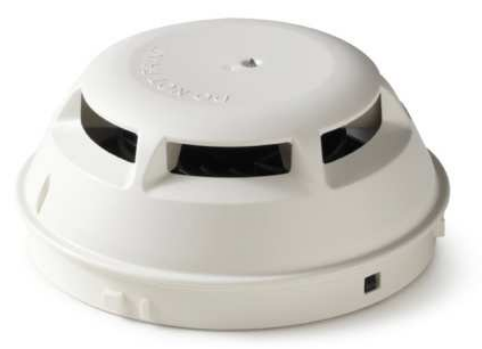

Figura 9. Detetor ótico de fumos

\subsubsection{Detetores térmicos do tipo pontuais}

Os detetores térmicos do tipo pontuais são utilizados em áreas onde a incêndios incipientes geram muito calor. Os detetores térmicos somente devem ser utilizados em áreas, onde existem fenómenos relacionados com o processo de fenómenos enganosos, tais como concentrações de aerossóis intensivos que tornam a utilização de outros detetores impossível. 
As áreas de aplicação típicas para detetores térmicos do tipo pontuais são:

- Cozinhas de cantinas com tetos baixos

- Interligação em instalações de refrigeração, onde existe uma névoa que é produzida pela condensação

- Salas de armazenamento de líquidos combustíveis, produzem pouco fumo em caso de incêndio (principalmente em combinação com detetores de chama)

A figura 10 mostra um detetor térmico.

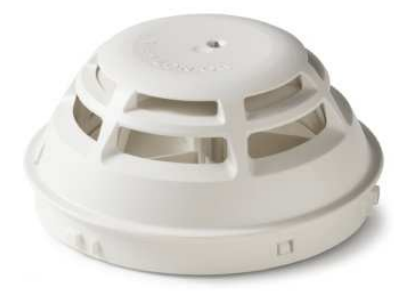

Figura 10. Detetor térmico

\subsubsection{Detetores multisensor do tipo pontual}

A utilização dos detetores de incêndio multisensor é porque detetam simultaneamente fumo e o constante aumento do calor. Devido à interligação inteligente dos sinais no sensor, tais detetores são caracterizadas por deteção precoce e altamente fiável do incêndio.

Eles são aplicados em todas as áreas onde a deteção precoce e elevada resistência aos fenómenos enganosos são de maior importância.

As áreas de aplicação típicas para os detetores de incêndio multisensor são:

- Escritórios, salas de conferência, quartos de hotel, restaurantes, etc, onde é permitido fumar;

- Quartos com kitchenettes em lares de idosos;
- Salas de produção, onde podem ocorrer fenômenos enganosos;

- Instalações de estacionamento para veículos a motor ou locomotivas diesel;

- Todos os tipos de edifícios de armazenamento (indústrias de abastecimento de alimentos e animais, instalações de refrigeração);

- Cozinhas de cantinas com tetos mais altos do que $3 \mathrm{~m}$;

- Discotecas e outros centros de eventos em que os aerossóis artificiais podem ser libertados.

A figura 11 mostra um detetor multicritério.

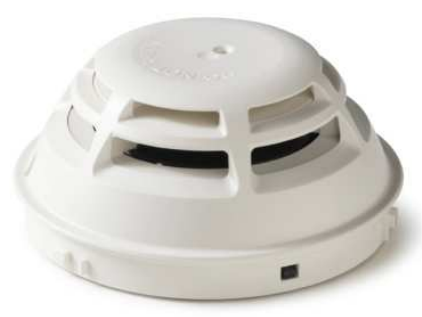

\section{Figura 11. Detetor multicritério}

\subsubsection{Detetores lineares de fumos}

Os detetores lineares de fumo são utilizados em áreas em que se espera que os incêndios incipientes produzam fumos e onde detetores de fumos do tipo pontual não podem ser utilizados.

As áreas de aplicação típicas para detetores lineares de fumos são:

- Espaços muito altos (átrios, hangares);

- Grandes salões em que a manutenção dos detetores do tipo pontual seria mais difícil ou mais cara do que o de detetores lineares de fumo;

- Áreas operacionais com forte risco de sujidade dos detetores do tipo pontual (serrações); 
- Edifícios históricos em que os detetores pontuais não são desejados por razões estéticas.

A figura 12 mostra um detetor linear de fumos.

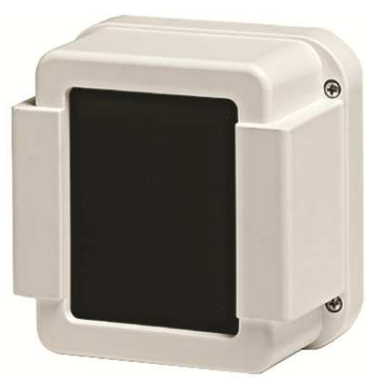

Figura 12. Detetor linear de fumos

\subsubsection{Detetores de fumo por aspiração}

Os detetores de fumo por aspiração são utilizados sempre que os incêndios produzam fumos e devam ser detetados o mais cedo possível, sendo que os detetores do tipo pontuais não são muito insensíveis ou não são suficientemente robustos contra a sujidade.

As áreas de típicas de aplicação para os detetores de fumo por aspiração são:

- Espaços com uma elevada concentração de propriedade valiosa onde mesmo pequenas concentrações de aerossóis devem ser detetadas (espaços de servidores, instalações de produção de chips);

- Salas muito altas onde a concentração de fumos abaixo do teto é fortemente diluído devido ao grande volume (átrios, hangares);

- Grandes salões em que a manutenção dos detetores do tipo pontual seria mais difícil, ou onde os detetores do tipo pontual seria essencialmente mais caro do que a deteção de fumos por aspiração;

- Áreas onde os detetores do tipo pontual são propensos a sujidade operacional (instalações de reciclagem, indústria de veículos pesados);
- Locais onde fortes fenómenos enganosos, tais como a previsão de condensação da humidade (áreas de entrada das instalações de refrigeração);

- Edifícios históricos em que os detetores de pontuais não são aconselhados por razões estéticas;

- Áreas com maior risco de vandalismo (Ex. prisões).

A figura 13 mostra um detetor linear de fumos.

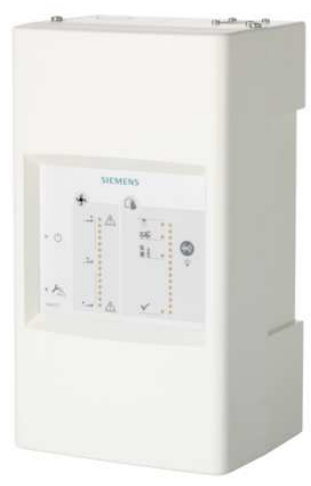

\section{Figura 13. Central de aspiração}

\subsubsection{Os detetores de chamas}

Os detetores de chamas são utilizados em áreas onde chamas podem ocorrer muito rapidamente e na monitorização de grandes áreas abertas.

As áreas de aplicação típicas para detetores de chama são:

- Instalações de armazenagem de combustíveis líquidos;

- Armazéns abertas ou plataformas de carga;

- Áreas de tanques de óleo ou combustíveis;

- Oficinas de pintura;

- Bancos de ensaio de motores;

- Instalações de reciclagem. 
A figura 14 mostra um detetor de chamas.

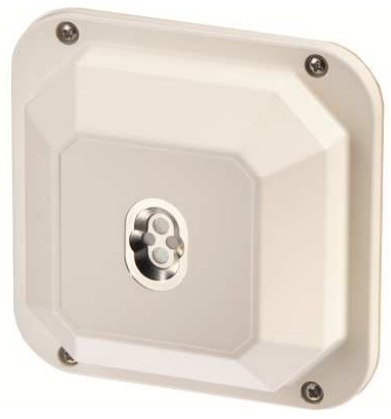

Figura 14. Detetor de chamas

\section{Conclusão}

Para se avaliar um sistema de deteção de incêndio, a qualidade requerida em relação ao comportamento de deteção e a confiabilidade da deteção deve ser claramente a prioridade. Só desta forma pode o objetivo da proteção definida ser alcançada, definindo o grau necessário de segurança pessoal, danos mitigação sobre imóveis e bens, bem como a limitação de interrupções operacionais e danos ambientais.

A facilidade de utilização, funções e integração adicional num sistema super coordenados são aspetos adicionais que devem ser tomados em consideração e para a avaliação. Com estes pontos, os custos adicionais que incorrem, na melhor das hipóteses, tem de ser comparados com o aumento de produtividade que podem ser atingidos. Esta pode estar sob a forma de ganhos de tempo, por exemplo, por uma melhor visão geral do sistema ou maior flexibilidade.

Durante a fase de projeto, é praticamente impossível determinar exatamente os custos totais de um sistema de deteção de incêndio. $O$ resultado pode ser mais ou menos preciso, dependendo como os diferentes aspetos são considerados. É importante que a determinação dos custos globais, para além dos meros custos de aquisição, se leve em conta a manutenção, a extensibilidade e os custos de extensão, bem como possibilidades de modernização.
Uma vida útil mais longa já levou a uma excelente rentabilidade, para muitos sistemas de deteção de incêndio, apesar de seus custos de aquisição serem inicialmente mais elevados.

É obrigatório ter em consideração esses fatores, para que uma avaliação mais ou menos correta possa ser efetuada. Só assim podem os custos globais ser determinados com a maior precisão possível, o que deve ser um pré-requisito para a escolha do sistema mais eficiente em termos de custos a longo prazo. Investir num sistema de deteção de incêndio com deteção de alta confiabilidade, alta flexibilidade e modernização conceito bem pensado paga-se.

\section{Investimento inteligente paga-se!}

\section{Referências bibliográficas}

[1] Gustav Hamilton: This is Risk Management, page 21

[2] 10 years average according to the building insurance of the canton of Zurich, Switzerland, 2003

[3] The Geneva Association Risk \& Insurance Economics, Geneva: World Fire Statistics 2003, page 5

[4] The Geneva Association Risk \& Insurance Economics, Geneva: World Fire Statistics 2003, page 4

[5] According to the German vfdb, "Arbeitsgruppe Brandforschung", total cost of German fire damages is higher than 6 billion $€$

[6] German FVLR, “Fachverband Lichtkuppel, Lichtband und RWA", D-32758 Detmold: "Brand Aktuell", No. 16/03

[7] E.g.: US property insurer Allendale Mutual and FVLR, "Fachverband Lichtkuppel", "Lichtband und RWA", "Brand Aktuell", Nr. 16/03

[8] Report No. 9, International Technical Committee for Preventive Fire Protection and Extinguishing 